\title{
1 \\ Mapping a Mirage: \\ Documenting the Scholarship of Teaching and Learning
}

Nicola Simmons

University of Waterloo

The purpose of the conference session upon which this paper is based was to challenge the notion that evidence of scholarship must be limited to publication in a peer-reviewed journal, and to open the doors for creative thinking about what might constitute evidence of scholarship of teaching and learning. Existing theory around defining scholarship (Boyer, 1990; Glassick, Huber, \& Maeroff, 1997; Sorcinelli, 2002) can provide a justification for alternatives, but how can scholarship expressed through teaching or other creative performance be demonstrated? Scholarship of Teaching and Learning (SoTL) scholars in particular may face challenges in documenting their scholarship so promotion and tenure committees can understand its worth.

My intent was not to negate the importance of peer-reviewed publications, but to parallel them with other forms of scholarly dissemination that I argue might in some cases have more impact on advancing the field. I also maintain that any understandings of scholarship are both individual and contextual (Baxter Magolda, 1999). The purpose of this summary therefore is not to promote a common definition but rather to challenge the traditional boundaries of understanding. Engagement in scholarship suggests an exchange of ideas, and it is my hope that this article may serve as a starting point for future discussion.

\section{Preamble}

I

should explain at the outset: my argument for an extended definition of scholarship is neither original nor new. Boyer, as long ago as 1990, recommended academics should "break out of the tired old teaching versus research debate and define, in more creative ways, what it means to be a scholar"(p. xii). Boyer's advice, I suggest, is not so much a call for organisational restructuring, but rather to individual 
academics to reassess what form their scholarship takes, and to determine a personally relevant definition.

On a personal note, I have often encountered the notion that alternatives would not carry the same weight as publication in peer-reviewed journals. My understanding of my own scholarship includes a desire to push the edges of knowledge, in this case, of what might constitute scholarship. I would be a poor scholar, I felt, if I stayed only with traditional perspectives, and made no attempt to explore new territory. At the same time, I want to situate any definition of scholarship to assist others rather than alienate them with my radial perspective. I must position myself, as Walzer (1987) suggests, "a little to the side, but not outside; critical distance is measured in inches" (p. 61), such that my scholarship is accessible not only to other early adopters, but also to those who might espouse more traditional approaches.

I think of the usefulness of Palmer's (1998) four-stage change framework as it might be applied to moving toward new understandings of scholarship. In stage 1, "isolated individuals make an inward decision," followed by stage 2 , in which "individuals begin to discover one another and form communities of congruence." In stage 3, "communities start going public," and in stage 4, a "system of alternative rewards emerges to sustain the movement's vision and to put pressure... on the standard institutional reward system" (p. 166). It is my hope that this article will prompt further discussions that might lead to communities of congruence going public, and ultimately to a renewal of institutional reward structures.

\section{Defining Scholarship}

Various lenses exist for defining scholarship. For example, Boyer (1990), in his widely quoted Scholarship Reconsidered, outlines the scholarships of discovery, integration, application, and teaching, and suggests that the same standards of evaluation should be applied in each as are used in research. Kreber (2003) notes the ongoing conversations in the literature around applying this definition of scholarship. For example, "based on a rather narrow interpretation of Boyer's (1990) work a presupposition of this discourse is that teaching, if done well (the assessment typically based on student ratings of instruction) is scholarship" (p. 29). Given that one can easily find examples in practice of teaching that is neither scholarly nor scholarship, what guidelines can be applied to define scholarship in teaching?

Glassick, Huber, and Maeroff (1997) outline six criteria for scholarship: evidence of clear goals, adequate preparation, appropriate methods, significant results, effective presentation, and reflective critique. Scholarship of teaching and learning is about planning, assessing, and modifying one's teaching (Boyer, 1990; Sorcinelli, 2002), a cycle which will be recognizable to anyone familiar with action research (Kemmis \& McTaggart, 1982) or reflective practice (Schön, 1983). Huber and Hutchings (2005) describe a process of "framing questions, gathering and exploring evidence, trying out and refining new insights in the classroom, and going public...in ways others can build on" (p. 21). This type of research is in no way limited to education faculty or faculty developers, and scholars of teaching and learning can and will emerge from any and all disciplines (Sperling, 2003; Weston \& McAlpine, 2003). In fact, it is critical that they do, and bring the perspectives of their disciplines to bear on scholarship in teaching.

On a historical note, Skeat (1993) points out that scholarship comes from the root schola, meaning "rest, leisure, employment of leisure time, also a school. Orig. 'a pause"' (p. 418), and that a scholar, or scholere was originally "a commentator" (p. 418). In its original form, then, dissemination of scholarship was not limited to peer-reviewed publication, and might, it seemed, even suggest something enjoyable.

The online Oxford English Dictionary (1989) defines scholarship as "the attainments of a scholar; learning, erudition; esp. proficiency in the Greek and Latin languages and their literature" (n.p.). While working knowledge of Greek and Latin (outside those terms found in one's own field) may no longer be considered a scholarly requirement, how should one measure attainments? The Merriam Webster Online Dictionary (2005) provides little clarification, describing scholarship as the "character, qualities, activity, or attainments of a scholar” (n.p.), or one 
who attends school or who has "done advanced study in a special field" (n.p.). How would these definitions, which seem much more holistic than simply peer-reviewed publications, compare to the formal understandings set out in collective agreements and university policies? What criteria must evidence of scholarship meet to be considered for the ubiquitous tenure and promotion process?

\section{Applying the Definition of Scholarship}

In order to see how these definitions were being applied in Canadian academic settings, I turned to statements from Canadian universities regarding the definition of scholarship. For example, Dalhousie University's Faculty of Health Sciences (1993) offered a definition encompassing a diversity of scholarship possibilities:

Scholarship is the application of systematic approaches to the acquisition of knowledge through intellectual inquiry. Scholarship includes the dissemination of this knowledge through various means such as publications, presentations (verbal and audiovisual), professional practice and the application of this new knowledge to the enrichment of the life of society. (n.p.)

Clearly this describes myriad possibilities, including presentations and practice. Teaching, in and of itself, could directly address "application of this new knowledge to the enrichment of the life of society."

The University of British Columbia, while acknowledging that published work is the usual form of evidence of scholarship, also allows that "distinguished architectural, artistic or engineering design, distinguished performance in the arts or professional fields, shall be considered in appropriate cases" (Brimner, 2004, n.p.). Further, the definition of scholarship indicates that "scholarly activity may be evidenced by originality or innovation, demonstrable impact in a particular field or discipline, peer reviews, dissemination in the public domain, or substantial and sus- tained use by others" (n.p.). Might one's teaching or conference presentations demonstrate "originality or innovation," or, if feedback from past students is an indicator, have a "demonstrable impact in a particular field?"

In addition, the Canadian Association for University Teachers (CAUT) position statement allows that

scholarship, the work of an academic, involves both the pursuit and the dissemination of knowledge through research, teaching, public lectures, conference communications, publications, the building of library collections, the provision of critically mediated access to information, artistic production and other similar activities. (CAUT, 2001, n.p.)

It seems the door is open to any number of alternatives in scholarly expression.

\section{Providing Evidence of Scholarship}

Conference presentations constitute evidence of scholarship; they do, after all, appear as peer-reviewed work on curriculum vitae, and the published abstracts do serve as retrievable evidence. To extend this idea, I have had the experience of attending a presentation at a conference, and hearing session attendees subsequently cite something said in their own presentations. Should this be considered differently than citations of a published article? Going beyond traditional understandings, if creative performance is an acceptable demonstration of scholarship, then perhaps conference presentations could be viewed in a similar way.

As a scholar, I must decide what I am seeking in order to consider presentations as evidence of scholarship. I value conference presentations that model excellent application of principles of education and that result in audience engagement and preferably dialogue. Scholarship arouses my curiosity and stimulates me to ponder the topic and share the results of my thinking with others. This should 
be true regardless of the form of the scholarship. For example, I expect to integrate my own research and reflection on practice to offer new insights into how to present a topic. The evidence of that scholarship will not be limited to whether attendees subsequently cite my session in their own work, but will include whether their own practice (and mine) is affected by their participation in my scholarship.

\section{Teaching as Scholarly Art: Developing Future Scholars}

If conference presentations count as scholarship, then what about workshops and classroom teaching? Do we need to write or speak to teaching colleagues about work for it to be scholarly, or could it be scholarship because it is a "distinguished performance in the arts or professional fields" (Brimner, 2004, n.p.)?

The emerging field of the Scholarship of Teaching and Learning (SoTL) positions teaching scholarship as undertaking empirical investigations of one's classroom practices. Further, "SoTL also involves disseminating the results we find in a public forum, so that when others hear about our practices, they are prompted into creating their own systemic changes" (The Faculty Center for Teaching and Learning, n.d.). There is room, therefore, to conduct research into one's teaching practices, planning for improvement, observing the results, and continuing to improve the plan and its implementation.

Some would argue that teaching can never be scholarship because it is not subject to peer review and that while conferences are presented to colleagues, and often are peer-reviewed, teaching is to students who do not have that level of experience. I suggest that this may reflect a limited short-term view of the definition of peer. Students often cite ideas discussed in their own work, some of which is subsequently shared more widely through presentation or publication. Should this be considered differently than citations of a published article? While my students may not all be my peers now (some are), many will be in just a few years. If I use a developmental approach now to encourage them to critique my teaching and their own response to it (Pratt, 1998; Brookfield,
1990), then at what point does this interaction become peer review of and engagement in scholarship?

It is up to me to encourage students to treat my teaching critically. It is up to me to support them in moving from student to peer, such that they are well placed to critique theorists and practitioners in the field (including me). This reflects my understanding of scholarship in my teaching: I model scholarship through responding to students' feedback and demonstrating critical reflection and improvement in practice, just as I would expect them to demonstrate growth and development in their course work. This moves them towards behaving as scholarly peers, such that there is peer-review of ideas discussed.

Clarke (2005) outlines five criteria for scholarship in teaching and learning. The teacher scholar, he says, identifies a problem related to teaching and learning, researches potential solutions, tries them out, assesses their success, and makes the research public - opening it up to peer review and discussion. I see the problem not, therefore, as whether or not teaching is scholarly activity, nor whether students constitute an audience of peers, but rather how I can provide evidence of this form of scholarship. Ultimately, regardless of what I may choose to personally understand, I must persuade an inter-disciplinary audience of peers, some of whom will espouse more traditional perspectives. Using Clarke's criteria may smooth the path towards acceptance of alternative forms of scholarship. Perhaps I could make my scholarship more immediately relevant by discussing my attempts at improvement in my practice with teaching colleagues, and in doing so, make public my teaching scholarship. I could engage in 'water cooler' scholarly conversations, thus involving other teaching experts in my cycles of reflective practice (Schön, 1983).

\section{The Reflection: Seven Practices for Promoting Scholarship}

The challenge, as I see it, is that many forms of alternative scholarship are difficult for others to retrieve, making substantiation of scholarly evidence difficult. If I want alternative activities to be considered as evi- 
dence of my scholarship, I need to consider ways of offering evidence of that scholarship.

1. Begin by engaging in teaching and presenting as if they were scholarly endeavours. Consider how Clarke's (2005) or Glassick, Huber and Maeroff's (1997) criteria could be used to inform my teaching improvements.

2. Cite scholarship of all kinds. Include others' conference presentations as well as published papers in written work. Cite students, and consider the ways in which this develops new scholars.

3. Include verbal citations of my work on my curriculum vitae. If someone attends my presentation and refers to it in his or her own verbal presentation, include that as a citation.

4. Consider the possibilities for scholarship in teaching. Go beyond action research in my teaching, taking also a long-term view. Consider the ways in which my scholarship is living in my students.

5. Seek out peer review for diverse forms of scholarly expression. Continue to video my teaching for critical review. Continue to make my teaching public. Set up a review group across several disciplines. Ask peers after conferences for comments on the scholarship of my presentation delivery as well as the content. Ask others to write teaching reviews much as they might write book reviews.

6. Gently nudge the edges of acceptable evidence of scholarship.

7. Recommend that each academic consider a personal definition of scholarship, just as they might articulate a philosophy of teaching.

\section{Conclusion}

From my perspective, there was a lovely synergy about the STLHE conference session: at the same time that I (hopefully) pushed the participants' thinking, I found myself re-considering my identity as scholar. To me, this is scholarship in play. In discussions with colleagues, I have often heard the opinion that alternative forms of scholarship are interesting, but nonetheless, they cannot be seen as scholarship until the peer-reviewed paper is available. It seems an academic's standing as a scholar is still dependent on the list of publications. Doesn't this undervalue the potential impact that teaching, conference presentations, media interviews, and other expressions of scholarship can have, not only on students, but also on the larger community, and ultimately, on the history of the discipline? Socrates wrote nothing - should he still be considered a scholar?

\section{References}

Baxter Magolda, M. (1999). Creating contexts for learning and self-authorship: Constructive-developmental pedagogy. Nashville, TN: Vanderbilt University Press.

Boyer, E. L. (1990). Scholarship reconsidered: Priorities of the professoriate. Princeton, NJ: The Carnegie Foundation for the Advancement of Teaching.

Brimner, T. (2004). Changes in the agreement on conditions of appointment for faculty. University of British Columbia. Retrieved December 10, 2005 from, http://www.hr.ubc.ca/ files/faculty_relations/ms_word_files/Changes_in_the_Agreement_on_Conditions_of_ Appointment_for_Faculty.doc

Brookfield, S. D. (1990). The skillful teacher. San Francisco: Jossey-Bass.

CAUT. (2001). CAUT Policy Statement on the Distribution of Workload and Sabbatical Leave. Retrieved on January 3, 2006, from http://www. caut.ca/en/policies/workload.asp

Clarke, M. (2005). The scholarship of teaching and learning: A community of practice perspec- 
tive. Retrieved on January 3, 2006 from, http://www.uottawa.ca/academic/cut/options/fev_05/ENG/article2_0.htm

Faculty of Health Professions. (1993). Scholarship definition. Dalhousie University. Retrieved on January 3, 2006, from http://healthprofessions.dal.ca/policy/scholardef.pdf

Glassick, C., Huber, M. T., \& Maeroff, G. I. (1997). Scholarship assessed: Evaluation of the professoriate. San Francisco: Jossey-Bass.

Huber, M. T., \& Hutchings, P. (2005). The advancement of learning: Building the teaching commons. San Francisco: Jossey-Bass.

Kemmis, S., \& McTaggart, R. (1982). The action research planner (2nd ed.). Burwood, Victoria, Australia: Deakin University Press.

Kreber, C. (2003). The scholarship of teaching: A comparison of beliefs held by experts and regular academic staff. Higher Education, 46, 123-141.

Merriam-Webster Online. (2005). Scholarship. Retrieved on January 5, 2006, from http:// www.m-w.com/

Oxford English Dictionary. (1989). Scholarship. Retrieved on January 5, 2006, from http://www. oed.com/

Palmer, P. (1998). The courage to teach. San Francisco: Jossey-Bass.

Pratt, D. D. (1998). Five perspectives on teaching in adult and higher education. Malabar, FL: Krieger Publishing.

Schön, D. (1983). The reflective practitioner. New York: Basic Books.

Skeat, W. W. (1993). The concise dictionary of English etymology. Ware, Hertfordshire, England:
Wordsworth Editions.

Sperling, C. B. (2003). How community colleges understand the scholarship of teaching and learning. Community College Journal of Research and Practice, 27(7), 593-601.

Sorcinelli, M. D. (2002). New conceptions of scholarship for a new generation of faculty members. New Directions for Teaching and Learning, 90, 41-48.

The Faculty Center for Teaching and Learning. (n.d.). What is the Scholarship of Teaching and Learning? University of Central Florida. Retrieved on December 10, 2005, from http:// www.fctl.ucf.edu/sotl/definition.html

Walzer, M. (1987). Interpretation and social criticism. Cambridge, MA: Harvard University Press.

Weston, C. B., \& McAlpine, L. (2003). Making explicit the development toward the scholarship of teaching. New Directions for Teaching and Learning, 86, 89-97. 